\title{
Ocio en un país imaginario. Identidad, alteridad y cuestiones genéricas en Idle Days in Patagonia (1893) de W. H. Hudson
}

Eva Lencina

Lencina, E. (2021). Ocio en un país imaginario. Identidad, alteridad y cuestiones genéricas en Idle Days in Patagonia (1893) de W. H. Hudson. Revista de Filología y Lingüística de la Universidad de Costa Rica, 47(1), e44400. doi: https://doi.org/10.15517/rfl.v47i1.44400

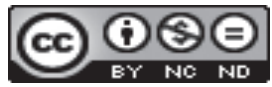

Doi: https://doi.org/10.15517/rfl.v47i1.44400

URL: https://revistas.ucr.ac.cr/index.php/filyling/index 


\section{Idleness in an Imaginary Country. Identity, Alterity and Genre Issues in W. H. Hudson's Idle Days in Patagonia (1893)}

\section{Lencina, Eva}

\author{
(iD) Eva Lencina \\ evalencina@live.com.ar \\ Universidad Nacional de Tucumán (UNT), \\ Universidad Nacional de Córdoba (UNC) y Consejo \\ Nacional de Investigaciones Científicas y Técnicas \\ (CONICET), Córdoba, Argentina
}

\author{
Revista de Filología y Lingüística de la Universidad \\ de Costa Rica \\ Universidad de Costa Rica, Costa Rica \\ ISSN: 0377-628X \\ ISSN-e: $2215-2628$ \\ Periodicidad: Semestral \\ vol. 47 , núm. 1, 2021 \\ filyling@gmail.com
}

Recepción: 04 Febrero 2020

Aprobación: 24 Marzo 2020

URL: http://portal.amelica.org/ameli, jatsRepo/125/1251597023/index.html

DOI: https://doi.org/10.15517/rfl.v47i1.44400
Resumen: Este artículo caracteriza algunos de los aspectos centrales de Idle Days in Patagonia (1893), del naturalista y escritor anglo-argentino William Henry Hudson. En esta obra, el autor rememora su estadía en el territorio patagónico entre 1870 y 1871 . Se busca examinar la obra desde la perspectiva imagológica y caracterizar la relación del sujeto con la imagen de sí y de los otros que se construye en el texto. Importa también la relación con el espacio, gracias a la cual se concibe el ocio como actividad intelectual productiva, que configura una representación del vínculo semimístico con la naturaleza. El núcleo de nuestro interés está puesto en la convergencia entre identidad y alteridad en el medio rural argentino decimonónico: el desarrollo de las estrategias hudsonianas de escamoteo de la identidad argentina en un texto escrito para Inglaterra, a la par de una búsqueda de empatía con la alteridad indígena in absentia. Se busca también discutir el estatuto genérico de un texto tan ambiguo como lo es Idle Days in Patagonia, que, como su autor, escapa a las clasificaciones. Finalmente, se compara brevemente esta obra de Hudson con una obra trunca de Eduardo Holmberg, debido a cómo el posicionamiento de cada autor en sus respectivos campos literarios echa luz sobre los modos de representación imaginaria del espacio patagónico.

Palabras clave: W H. Hudson, Idle Days in Patagonia, literatura comparada inglesa-argentina, imagología, frontera.

Abstract: This paper characterizes some of the central aspects in Idle Days in Patagonia (1893), by Anglo-Argentine naturalist and writer William Henry Hudson. In this work, the author recalls his stay in the Patagonia territory between 1870 and 1871. We aim to examine the work from the perspective of Imagology, and characterizing the subject's relation con his self-image and the hetero-image that is developed in the text. Due to the relation with space, idleness is conceived as a productive intellectual activity that shapes a representation of the semimystic link with nature. The focus of our interest is the convergence between identity and alterity in the Argentina rural environment of the 19th century: the development of Hudson's strategies of swindling his Argentine identity in a text written for English readers, along with a search for empathy with the indigenous alterity in absentia. We also aim to discuss the genre statute in a text as ambiguous as Idle Days in Patagonia, which, like its author, escapes classifications. Finally, we briefly compare this 
work with an unfinished work by Eduardo Holmberg, due to how the stance each author takes in their respective literary fields enlightens the manners of imaginary representation of the Patagonia space.

Keywords: frontier, W H. Hudson, Idle Days in Patagonia, Comparative Literature English-Argentine, Imagology, frontier.

My state was one of suspense and watchfulness: yet I had no expectation of meeting with an adventure, and felt as free from apprehension as I feel now when sitting in a room in London. The change in me was just as great and wonderful as if I had changed my identity for that of another man or animal.

(Hudson, 1893, p. 216, Idle Days in Patagonia).

\section{INTRODUCCIÓN}

En 1893 William Henry Hudson publica Idle Days in Patagonia basado en notas y recuerdos de juventud de un viaje que había realizado a fines de 1870 por territorios adyacentes al Río Negro. El texto posee una dimensión autobiográfica que se entrecruza con el género del relato de viajes por la temática del desplazamiento que aborda, género que a su vez subvierte bajo la impronta de un estatismo reflexivo, mucho más acorde a su idea de relación con la naturaleza.

Si en The Purple Land, su carta de presentación en el campo literario inglés de 1885, Hudson recurría a su experiencia de vida en Sudamérica para entretejer una ficción con apariencia de relato de viaje (estructurada sobre la base de la peripecia novelesca y sobre una tesis apologética de la barbarie), en esta primera etapa de su escritura echará mano con frecuencia del mismo escenario. Idle Days in Patagonia, junto con The Naturalist in La Plata (1892/1895), publicado el año anterior, inaugura la matriz de escritura donde el autor mejor se desenvuelve. Un tipo de texto ecléctico, que aúna el ensayo de descripción de la naturaleza, la autobiografía y la estampa de costumbres. A tal punto contiene Idle Days los principales tópicos de la escritura hudsoniana que Guillermo Ara (1954) lo considera un texto seminal:

El libro contiene sin embargo un material tan abundante de investigaciones, que podría afirmarse que cuanto escribió después tiene aquí su arquitectura más íntima. En este aspecto no hallaremos nada que se le acerque hasta la publicación de su obra póstuma. Dias de ocio... resulta como una entrega anticipada de Una cierva en el Richmond Park. (p. 160).

Sin embargo, una diferencia fundamental con The Purple Land debe ser notada: mientras que las aventuras de Richard Lamb transcurren en un escenario natural transido por personajes característicos del mundo semicolonial (los ingleses entregados a la barbarie de la caza y el alcohol fuera de su país natal -una secuencia que connota en sí misma toda una construcción de imagen de lo nacional-, el escocés que encontró su lugar en el mundo, gauchos sabios y bárbaros, jovencitas criollas que enamoran, el caudillo Santa Coloma, etc.), los vagabundeos autobiográficos narrados por Hudson en Idle Days tienen la particularidad de prescindir en gran medida del contacto con los otros. Se incluyen varios encuentros con personajes que le refieren historias de la zona (en cuyo caso, importa más la anécdota que su narrador), pero Hudson explicita que prefiere y busca la soledad. Esta diferencia refuerza el carácter novelesco de The Purple Land.

Dentro de su obra, este es uno de los primeros textos donde se ofrece un acceso más directo a las representaciones de la identidad hudsoniana. Esto abre posibilidades de abordaje que aprovecharemos desde la noción de pacto autobiográfico(Lejeune, 1994) y desde la relación que el yo autoral establece con su entorno adulto, en comparación con Far Away and Long Ago (1918), la autobiografía de infancia y juventud donde el autor retrata su vida en una comunidad anglosajona de la pampa, que abordaremos en un capítulo posterior. 
A partir de esta primera aproximación a la identidad hudsoniana, también serán de nuestro interés los primeros indicios que aparecen en su obra de una alteridad radicalmente opuesta a la propia identidad, pero con la cual busca conectarse. La figura del indígena in absentia se articula como una figuración que, en su valor imagológico ${ }^{1}$, repone numerosos perfiles de esa semiotización de la frontera ${ }^{2}$ que propone Hudson, una frontera construida como espacio representado, pero también como un permeable límite simbólico entre lo propio y lo otro.

Existe en torno a Hudson una tendencia biográfica por parte de la crítica, que ha tendido a interpretar sus obras en relación directa con la vida del autor. Esto no solo oscurece la lectura de obras como The Purple Land, sobre la cual el mismo Hudson tuvo que aclarar que no narraba sus propias experiencias, sino que tiende a simplificar la lectura de otras, como la que nos ocupa. Según Jaime Rest (en Barrenechea, Jitrik y Rest, 1981), refiriéndose a Far Away and Long Ago, la recepción de Hudson tiende a hermanarlo con la tradición de los viajeros ingleses y "funcionalizarlo" en este contexto:

Con excepción de la sagaz actitud asumida por unos pocos críticos, en general es muy curioso y marginal el uso que se hizo hasta el presente del libro de Hudson en Argentina. En el ansia de reconstruir o robustecer un sentido de la tradición, se ha preferido emplearlo como documento, a semejanza de los abundantes testimonios que han dejado los viajeros europeos (especialmente ingleses) acerca de las costumbres y las formas de vida rioplatenses a mediados del siglo XIX, con absoluto desdén por los valores poéticos. (pp. 99-100).

La vinculación de Hudson con otros viajeros ingleses en el Río de la Plata, por una general similitud de orígenes y trayectorias, hace que la lectura de Idle Days también esté signada por esta connotación de la literatura de viajes (Mónica Szurmuk, 2001, párr. 12, como veremos, lee la obra dentro de este género). Nosotros buscaremos otras consideraciones genéricas que echen luz sobre un texto poroso, digresivo y reacio a clasificaciones genéricas como es el de Hudson.

\section{OCIOSAS CONVENCIONES LITERARIAS Y UN TEXTO QUE SE DISUELVE}

Idle Days in Patagonia se publicó en 1893 por la editorial Chapman \& Hall. Hudson escribe este fallido relato de viajes en una época bisagra en su trayectoria, en la que empieza a desprenderse de sus primeras ficciones de ambiente mayormente sudamericano y a incursionar en sus primeros ensayos de ornitología argentina e inglesa. Podría decirse que Idle Days in Patagonia tiene un pie en cada lado: bebe aún de los recuerdos sudamericanos de Hudson que venían alimentando sus ficciones, pero se permite mayor anclaje autobiográfico para contextualizar sus digresiones sobre la naturaleza ${ }^{3}$.

Si bien Idle Days y The Naturalist in La Plata podrían leerse en tándem, como textos complementarios que inauguran la escritura ecléctica de Hudson (y, de hecho, fueron ambos muy leídos en Argentina), consideramos que el primero representa de forma más acabada y compleja el viraje desde una identidad filtrada por disparadores ficcionales y una reconstrucción memorística que inaugura ese programa autobiográfico cuya cima será Far Away and Long Ago. Idle Days, por su parte, contiene la recolección de una experiencia semimística que fue cardinal en la cosmovisión hudsoniana: el retorno de lo reprimido por la sociedad (el instinto salvaje) como puerta de la imaginación y principio de valoración del contacto con la naturaleza. En la cosmovisión hudsoniana, ambas dimensiones (civilización y barbarie) hacen a un hombre completo (a pesar de que esta cosmovisión es también contradictoria por momentos). Tal vez la temporada en la Patagonia fue para Hudson un viaje iniciático.

De hecho, Luis Horacio Velázquez (1963) encuentra un vínculo entre este período de calma y felicidad en la vida de Hudson y su posterior decisión de partir hacia Londres, justo cuando en Argentina observaba ciertos cambios sociales que rompían esa paz: "De sus meditaciones y apuntes, no solo nació el libro de sus ocios patagónicos, también, en gran parte, la determinación cercana que cambiaría el rumbo de su vida” (p. 127). Hudson compuso esta reminiscencia basándose en las notas de un viaje que emprendiera a la Patagonia 
en 1870 con el propósito de estudiar las aves de la zona y la esperanza de descubrir nuevas especies (de hecho, descubrió dos nuevas especies que hoy llevan su nombre, véase Jurado, 1988, p. 64).

El viaje de Hudson toma lugar durante 1871 y dura alrededor de un año, aunque la información biográfica difiere ligeramente en los detalles ${ }^{4}$. La acción comienza in medias res, con el narrador atrapado en un endeble vapor que lo lleva hacia Río Negro, donde comenzará el viaje por tierra, el tipo de viaje con el que es más fácil identificar a Hudson ${ }^{5}$. Detalles más bien novelescos abren la narración: la tripulación intenta huir en medio de la tormenta y dejar a los pasajeros a su suerte, con el capitán anciano y gravemente enfermo, pero el primer ingeniero, un inglés, los detiene a punta de pistola (Hudson, 1893, p. 3). Jason Wilson (2015, p. 111) especula con que probablemente estos detalles y el naufragio del primer capítulo sean invención de Hudson, ante la falta de registros históricos que corroboren el hecho.

Gisle Selnes (2003) ha señalado la relación entre el exilio y el motivo del naufragio en la literatura hispanoamericana. Esto cobra aún más importancia si lo relacionamos con la categoría existencial que Jean Franco (1980) adjudica a Hudson, la del "exiliado nato" (término que se refiere tanto a su original inadecuación a Argentina, debido al origen familiar, como al exilio espiritual en Inglaterra, puesto que su traslado fue voluntario). Selnes relaciona esta metáfora con las reflexiones de Jorge Luis Borges sobre la potencialidad productiva de la marginalidad en "El escritor argentino y la tradición" (1951). Resulta significativo, entonces, que Hudson delimite el espacio del exilio simbólico mediante un naufragio (en especial si este acontecimiento es, como cree Wilson, 2015, un agregado novelesco) e ingrese luego a un territorio donde su creatividad se dispara gracias a una separación autoimpuesta de la sociedad, un ingreso a ese territorio de frontera cultural donde, siguiendo la semiótica de Lotman, hay una actividad más intensa de significación.

Hudson enuncia los motivos espirituales, pero, principalmente, los pragmáticos de su viaje: la investigación in situ de la zona a la que ciertas aves migran y anidan (1893, pp. 5-6). Recordemos que en la época de este viaje ya había mantenido correspondencia científica con la Smithsonian Insitution de Washington y ahora con la London Zoological Society (de la que llegó a ostentar el título de miembro corresponsal), la cual, si bien no financió la excursión, sí fue la destinataria de algunas muestras y del relato de los descubrimientos de Hudson (Tomalin, 1982, pp. 84-92).

Aunque estas fueran sus filiaciones científicas en el presente de la narración, en el momento de la enunciación Hudson elige desligarse de los demás ornitólogos, de los que dice desconocer sus sentimientos (1893, p. 6). Así, es importante destacar que esta es una obra de tiempos heterogéneos: existe una gran distancia entre el momento de la narración (1870) y el de la enunciación (1893), dos décadas en las cuales el pensamiento de Hudson maduró y sufrió importantes cambios. Uno de ellos es notorio: mientras que durante su viaje a la Patagonia se encarga de cazar aves y recolectar muestras para enviarlas a los ornitólogos de la Zoological Society, en el mismo texto reflexiona acerca del horror que le produciría luego ver, recién llegado a Londres en 1874 (notemos que no mucho después de su excursión), cuerpos embalsamados de aves en el estudio de un naturalista. Si bien no desaprueba abiertamente la caza o la recolección de muestras con fines científicos, se aleja de estas prácticas durante sus caminatas por la campiña inglesa (decantándose solo por la observación) y ayuda a fundar también la Royal Society for the Protection of Birds en 1889. Este componente de alteridad en su imagen (el construirse a sí mismo como un anglosajón criado en la naturaleza de un territorio semicolonial) es el que concede legitimidad a su postura ecológica, postura que cobra relevancia y termina de definirse cuando Hudson entra en contacto con la vida en una ciudad industrializada como Londres. Esta autoimagen exotizada como garantía de autoridad ecológica se pondrá en juego en Green Mansions (1904/1937) y en los vínculos que establece esta novela con el eco-romance victoriano. En los cuentos de El Ombú (1902/1920), la articulación imagológica de la alteridad en sus textos (especialmente ese otro más radicalmente inasimilable como lo es el nativo americano) presenta claras diseminaciones y connotaciones hacia la cuestión de lo animal como un otro. 
Por otro lado, Mónica Szurmuk (2001, párr. 10) señala que la recepción del texto de Hudson en Inglaterra estuvo parcialmente condicionada por el hecho de coincidir con el momento en que Argentina ofrecía en Inglaterra los territorios patagónicos al mejor postor. Szurmuk especula entonces que la publicación de Idle Days tuvo la función editorial de difusión comercial (con Hudson tendiendo una suerte de trampa, pues la Patagonia funciona en su obra más como una ausencia). Las ofertas de tierras llegaban desde el gobierno argentino, pero falta evidencia que permita establecer un vínculo entre una editorial como Chapman \& Hall y las políticas de atracción de inversores de los gobiernos de Pellegrini o Sáenz Peña. Sí cabe especular, aun así, con una coincidencia entre el momento de publicación y la mayor popularidad de Argentina en Inglaterra a raíz de estas ofertas, lo que pudo haber ayudado a la publicación y difusión de esta obra de Hudson y de subsiguientes textos.

A pesar de sus intenciones, lo cierto es que el viaje de Hudson resultó ser técnicamente un fracaso. Poco después de llegar, sufrió un desafortunado accidente: examinando el arma de su amigo, se disparó en la rodilla y esto limitó por completo sus excursiones (1893, pp. 22-23). No se adentró demasiado en la Patagonia no cartografiada y, en cambio, dedicó su tiempo a vagabundear por las cercanías, observando la flora y la fauna, en un estado de contemplación semimística cuya descripción se convirtió en el centro de su ensayo. Heidi Liedke (2018, p. 150) considera que la herida habilita la adopción de la máscara del ocioso. Para terminar el viaje con ironía trágica, las muestras más valiosas recolectadas por Hudson durante sus exploraciones se pierden en el tránsito de vuelta a Buenos Aires. El autor dice que esto le dolió más que el disparo en la rodilla (1893, p. 38).

Si en The Naturalist in La Plata la identidad se asentaba en la definición de la profesión (por más que fuera en su vertiente más diletante y autodidacta), en Idle Days la idea de observación se proyecta hacia sus connotaciones de ocio, que ponen en juego la dinámica entre productividad del viaje científico e "improductividad" del viaje espiritual.

Es la frustración del viaje aquello que sienta la base para la impugnación del género del relato de viaje, como veremos más adelante, la que redirige la obra de Hudson hacia lo que tal vez pueda considerarse una variante de la literatura de viajes. En tal sentido, Enriqueta Morillas Ventura (2005, p. 457) considera que los relatos de ocio constituyen una suerte de subgénero, de culminación del relato de viajes.

Si bien Jason Wilson (2015, p. 16) es de la opinión de que el título mismo de la obra constituye una contradicción, debido a que la natural curiosidad de Hudson y su crianza puritana le habrían impedido los placeres de estar ocioso, lo cierto es que el naturalista se hace eco de una larga tradición de textos "ociosos" que pueblan la literatura inglesa desde el prerromanticismo a fines del siglo XVIII.

El título escogido por Hudson es, de hecho, uno de los mejores ejemplos de la proliferación de una constelación léxica referida al ocio (idle, rambling, roving, strolling) en crónicas de viaje victorianas de la segunda mitad del siglo XIX. En este sentido, forma parte de una toma de postura que defiende los valores de una suerte de ocio creativo "against the Victorian work ethos and capitalist esteem for 'useful' and economically profitable work" (Korte, 2014, p. 221).

Heidi Liedke (2018, p. 22) ha estudiado en detalle esta obra de Hudson, en relación con la tradición inglesa de literatura centrada en el concepto de ocio, la cual también se plantea como una suerte de reivindicación de un modo de vida social abandonado al final del período de la regencia y el asentamiento definitivo del modelo industrial, que plantea un aceleramiento percibido como desenfrenado en muchos aspectos, desde lo comercial hasta lo social y vital.

La obsesión con el trabajo y la productividad fue un factor cardinal en la conformación de la identidad inglesa durante el período victoriano (Liedke, 2018, p. 25). Es interesante cómo, entonces, Hudson aspira a adoptar en muchos aspectos una identidad inglesa (no insistiendo en sus orígenes argentinos, adoptando géneros literarios de la tradición inglesa como este mismo relato de viaje ocioso o la utopía de $A$ Crystal Age, publicada en 1887), pero no sacrifica por completo sus principios antiindustrialistas, sino que busca para ellos un refugio dentro de su nueva identidad. En este aspecto, se alinea con los románticos, entre quienes 
el ocio había sido una actividad practicada como fuente de inspiración poética y espiritual; de esta forma, se constituye en una suerte de viajero tardo-romántico en la época victoriana. Esto se relaciona con cierto pastoralismo ${ }^{6}$ al que se adhiere Hudson: el regreso a escenarios rurales, su oposición a la sociedad industrial, el ideal regresivo, etc., todos factores que hacen que Jean Franco (1980, p. XXIX) lo considere entre otros pastoralistas ingleses, muy anteriores, como Richard Jefferies, William Cobbett y Mary Russell Mitford. Por su parte, Liedke (2018), distanciando a Hudson del petulante turista victoriano, lo define como un idler (p. 157) y concluye:

Hudson's idling and fitful writing stands in line with my argument that the authors and travellers writing with a lateRomantic mentality were celebrating a mode of writing that stood both against the grain of more common contemporary literary practices such as Realism but was taking up a tradition that was still residual within the conceptual framework. In Hudson's case, the liminality of the Patagonian landscape facilitates a return to seemingly outmoded literary traditions. (p. 159 , el subrayado es nuestro).

Resulta interesante cómo aquí Liedke resalta el matiz anacrónico de los recursos que Hudson utiliza para ingresar al campo literario inglés. Esto se hace evidente si comparamos su tendencia a la poligrafía monográfica con los, en cambio, fuertes resortes de narrativa psicológica que se pueden encontrar en contemporáneos análogos temáticamente como Joseph Conrad o Rudyard Kipling. Cunninghame Graham comparte con Hudson esta forma de escritura anacrónica, aunque en el escocés parecería más una marca de aristocracia que de diletantismo.

Liedke (2018) también señala el espacio liminar de la Patagonia como posibilitador de este retorno a tradiciones literarias arcaicas. Así, Hudson busca una zona fronteriza donde su identidad escindida (ni argentino, ni inglés; ni escritor, ni naturalista; escindido entre el campo y la ciudad, la naturaleza y la cultura, etc.) encuentra mejores posibilidades de expresión. Esto coincide con las consideraciones de Iuri Lotman (1996) cuando habla de la frontera como un espacio físico, que no por eso deja de tener una carga semiótica:

En los casos en que el espacio cultural tiene un carácter territorial, la frontera adquiere un sentido espacial en el significado elemental. Sin embargo, también cuando eso ocurre, ella conserva el sentido de un mecanismo buffer que transforma la información, de un peculiar bloque de traducción. (p. 14).

Hacia el final de la obra, las digresiones protagonizan la narración en tiempo presente y la estructura de viaje termina por disolverse en reflexiones sobre el sentido del olfato: rasgo anticlimático que caracteriza el estilo hudsoniano. El autor no nos cuenta cuándo terminó su viaje ni cómo volvió a casa.

\section{EsTAR SOLO EN MEDIO DE LA NADA}

El capítulo XIII de Idle Days, “The Plains of Patagonia” está dedicado por entero a la reflexión sobre la especificidad del espacio patagónico. Allí, Hudson lo define como dotado de características especiales. El vacío de la Patagonia es el espacio donde el hombre puede reencontrar un estado primitivo que lleva siempre reprimido. Ese estado ante-racional, propio del "bárbaro", permite una contemplación plena de la naturaleza que también le compete al hombre civilizado, puesto que otorga libertad a la imaginación. Por momentos, incluso, Hudson pone imaginariamente al "salvaje" que supone extinto en el mismo nivel que los animales. Aquí entra en funcionamiento el motivo de la sociedad/civilización como atadura (Hudson la compara de hecho con un capullo invisible), en oposición a la barbarie como libertad (sin duda estamos ante el autor The Purple Land). Según Hudson, en el solitario y amplio espacio patagónico es posible sentir con mayor intensidad la antigua armonía perdida entre el organismo y el medio (1893, pp. 221-222). Un espacio vacío que se opone a los peligros novelescos del Far West norteamericano, saturado de signos, y se acerca más a las exploraciones de los pioneros canadienses y a las que luego se harían de los polos. Sin embargo, en sus reflexiones acerca de la Patagonia, Hudson hace sistema con una serie de viajeros ingleses que han reflexionado sobre la extrañeza y potencialidad del mismo espacio: desde su precursor Darwin hasta viajeros más modernos 
como Paul Theroux y Bruce Chatwin (para un análisis más completo de este tema, véase Livon-Grosman, 2003).

Solo en medio de ese vacío es que Hudson entra en una suerte de estado que trasciende la racionalidad, mediante un regreso a la mente del "salvaje". La mente pasa de ser "a thinking machine" a una máquina de "unknown purpose" (1893, p. 216), para a la vez adquirir una nueva identidad, la de otro hombre o animal. Hudson lo define como:

[...] the feeling experienced on going back to a mental condition we have outgrown [...]. I had undoubtedly gone back; and that state of intense watchfulness, or alertness rather, with suspension of the higher intellectual faculties, represented the mental state of the pure savage. (1893, p. 222).

Morillas Ventura (2005, p. 463) nota que son los pájaros (como emblema de la naturaleza) los que dictan los límites del espacio patagónico liminar con sus migraciones. Hudson quiere visitar ese territorio porque ahí es a donde partían los pájaros que siempre observaba desde Quilmes y Chascomús. Así, la Patagonia no es para él un territorio cultural (el de la frontera que separa la civilización de los indios), sino natural (reserva de vida salvaje), en todo caso la frontera en que acaba la ineludible presencia humana, donde se encuentra ya libre de obligaciones sociales y puede entregarse plenamente al contacto con la naturaleza. De hecho, el acceso al Río Negro no era posible por tierra y Hudson se traslada de Buenos Aires directamente a la Patagonia en barco, de alguna manera salteando el cruce de la frontera. Esto parecería distinguirla de la espacialidad canónica de relatos de frontera como el de Mansilla (Una excursión a los indios ranqueles), que además lidian directamente con comunidades indígenas y que hacen del cruce una instancia simbólica.

Roberto Díaz (en Gómez y Castro-Klarén, 2012, p. 94) lee la Patagonia hudsoniana como un espacio vacío, sin historia y sin lengua, donde el anglo-argentino subvierte la dicotomía civilización-barbarie a través de una indagación en la mente del "salvaje”. Tal vez debamos recordar que Hudson no leyó a Sarmiento y que civilización-barbarie, en tanto dicotomía fundacional del pensamiento argentino, es una herramienta de construcción política y humana de un estado-nación, del que Hudson nunca acusa recibo. Sería mejor decir que la literatura argentina del siglo XX (tal como veremos en la segunda parte de nuestra investigación) elige leer en Hudson una subversión de esa ya clásica dicotomía, antes que postular que es Hudson quien la problematiza.

Alicia Jurado (1988) estuvo entre los primeros críticos argentinos en estudiar en detalle la vida de Hudson en Inglaterra y, sin patriotismos (aunque desde una discursividad conservadora), supo ver claramente cómo el anglo-argentino concebía su terruño:

[...] en Inglaterra, Argentina es la tierra de su añoranza. Pero lo que añora, entendámoslo bien, no es un país como entidad social ni política, ni una comunidad humana: añora un paisaje bravío, una soledad salvaje que fue suya pero que le gustaría mucho menos ya con los colonos y las alambradas [...]. Añora una topografía, una flora, una fauna; no una nación. (p. 18).

Entonces, lo que en el campo literario argentino se leería inevitablemente a través de la dicotomía política civilización-barbarie, para Hudson corresponde a otro sistema, podríamos decir que diacrónico antes que sincrónico: Hudson piensa "antes éramos todos bárbaros", en vez de percibir una convivencia entre ambos términos, en la cual Sarmiento señala la obligatoria elección de la civilización como condición sine qua non para la construcción de un estado moderno. Si en Sarmiento la barbarie es la ausencia de educación, en Hudson es la presencia de otro tipo de conocimiento, la empiria originaria del hombre primitivo, que para todo hombre moderno debiera constituir una regresión a lo genuino. De este modo, el funcionamiento imagológico del pensamiento hudsoniano se fundamenta en lo que hoy podemos percibir como una resemiotización del ideario sarmientino.

En Argentina, Hudson es recuperado a partir del criollismo, cuando la figura del gaucho ya extinto se proponía como el mitológico pasado bárbaro (que ahora se alababa en una inversión del binomio, como bien nota Piglia, 1978, p. 23); pero la dicotomía argentina se actualiza y sigue siendo sincrónica, porque 
la amenaza bárbara ahora es representada por el inmigrante, a quien se quiere neutralizar enarbolando emblemas nacionales, tal como se pretendió con la nacionalización y canonización de Hudson.

Hudson se encandila románticamente con lo inasimilable de la prehistoricidad bárbara. En este sentido, entronca en cambio con la larga tradición anglosajona del civilizado que, en tierras lejanas, recupera perimidas formas de percepción (Stevenson, Conrad, Kipling), tradición que en Hudson se repliega más bien hacia un intimismo de la observación antes que hacia formas regresivas de virilidad. Hudson disuelve el concepto de aventura con una sensibilidad aprendida, en cambio, de los trascendentalistas norteamericanos.

Finalmente, Hudson lo dice: “[...] It is because in our inmost natures, our deepest feelings, we are still one with the savage" (1893, p. 231). La diacronía se revela sincronía. En esta cosmovisión hudsoniana se plantea la convivencia (ignorada pero debida) de civilización y barbarie en el hombre moderno, no en una disyunción ideológica como en Argentina. Ya con esto Hudson está dando muestras del imaginario que marcaría los primeros rumbos de la antropología en la era victoriana, que buscaba (con mayor o menor complacencia) en las costumbres de los pueblos "salvajes" rastros del origen del hombre "civilizado".

A pesar de las consideraciones más poéticas que elabora en este capítulo, a la hora de resumir su postura, Hudson opta por explicitar sus conclusiones de esta manera: el salvajismo no es respetable, pero sí útil como una suerte de limpieza espiritual o social refrescante, necesaria hasta que la sociedad sea más justa, lo cual podría suceder presumiblemente mediante una incorporación parcial de principios "salvajes" (difícil no percibir aquí ecos de esa célebre noción del "buen salvaje" que Rousseau postulara en su Discurso sobre el origen de la desigualdad entre los hombres). Esta es técnicamente la misma postura final de The Purple Land: se tolera y alaba la pervivencia de modos de vida "salvajes", pero no se llega a plantear la conveniencia de adoptarlos permanentemente. Hudson mantiene las convenciones epocales, empezando por el término "salvaje", pero sugiere dentro del mismo nuevas significaciones:

There is then something to be said in favour of this animal and primitive nature in us. Thoreau, albeit so spiritually-minded, could yet "reverence" that lower nature in him which made him brother to the brute. He experienced and fully appreciated its tonic effect. And until we get a better civilization more equal in its ameliorating effect on all classes -if there must be classes - and more likely to endure, it is perhaps a fortunate thing that we have so far failed to eliminate the "savage" in us the "Old Man" as some might prefer to call it. Not a respectable Old Man, but a very useful one occasionally, when we stand in sore need of his services and he comes promptly and unsummoned to our aid. (1893, p. 234).

Justamente a partir de la idea de liminalidad (Thomassen, 2009) que recupera Liedke (2018, pp. 151-153) cuando considera la Patagonia como un espacio liminal que alimenta la imaginación, o del concepto de zona fronteriza que plantea Mary Louise Pratt (2011), es que podemos empezar a reconocer la identidad hudsoniana. Reparemos en Hudson como ese sujeto fronterizo que encuentra en el vacío de la Patagonia su locus amoenus desde el cual pensarse a sí mismo en relación con el pasado (el "salvaje") y el presente (la civilización inglesa). Es interesante lo que plantea Lotman (1996) con respecto al desarrollo histórico del núcleo cultural de una semiosfera. El núcleo actual, la sociedad inglesa con respecto a la cual se piensa Hudson:

[...] es ya una nueva estructura surgida en el curso del desarrollo histórico, pero que se entiende a sí misma en metacategorías de las viejas estructuras. La oposición centro/periferia es sustituida por la oposición ayer/hoy. (Lotman, 1996, p. 15).

Sin embargo, existe un quiebre entre esa experiencia mística de compenetración en el propio sustrato "salvaje" y su posterior expresión a través de ese intelecto despreciado y de las convenciones literarias de una sociedad que Hudson considera estragada y ciega a las experiencias esenciales. Lo que Díaz (en Gómez y Castro-Klarén, 2012) llama la "nada preverbal” (p. 85) paradójicamente exige una expresión:

[...] esa nada primordial, curiosamente, se transmite por medio de una serie de lógicas palabras escritas, un pensamiento razonablemente expresado de modo verbal, y el contraste entre el estado de ánimo deseado por Hudson y el apretado texto de su libro no es un mero problema de representación. La práctica de la escritura y el acto de la lectura, esas meditadas acciones que ocurren por lo general a puertas cerradas, contrastan en efecto con la nada de los vertiginosos espacios abiertos. (pp. 102-103). 
Lo que menciona Díaz es uno de los principios de quiebre y escisión de la identidad hudsoniana, la imposibilidad del anglo-argentino para congeniar realidades que percibe como opuestas en su experiencia vital. El equilibrio que Hudson encuentra en la soledad patagónica es irrecuperable fuera de ese espacio.

El vacío que Hudson encuentra en la Patagonia, junto a su crianza en un medio rural aislado y su experiencia de una Buenos Aires previa a la modernización urbana de la generación del ochenta, sumado a su identificación por lo menos parcial con la autosuficiente comunidad de ingleses en esta ciudad, contribuye a su falta de visión estatal de Argentina, a la cual se refiere por lo general como Sudamérica (aunque en esta obra encontremos algunas menciones más de "Buenos Ayres").

Si lo imaginario en términos sartreanos se define en tanto ausencia del objeto(Sartre, 2005), es entonces ante la ausencia de Argentina en tanto nación que Hudson elabora un "país imaginario". Es decir, en términos imagológicos, podemos hablar del país como una imagen que en Hudson toma la forma de un territorio semicolonial de la infancia donde se cifra la naturaleza. Un país arquetípico definido principalmente por la flora, la fauna y por sus hombres semibárbaros (los gauchos) y bárbaros (los indios), en oposición a la Argentina "explotable" que veían los viajeros ingleses. Morillas Ventura (2005, p. 457) destaca justamente esta fusión hudsoniana de racionalismo y sensibilidad por la naturaleza con la que el autor construye el "imaginario de la Patagonia".

\section{El escamoteo de la ARgentinidad}

Phillipe Lejeune (1994, p. 50) establece las condiciones que un texto debe cumplir para ser considerado como autobiográfico cuando lo define como "relato retrospectivo en prosa que una persona real hace de su propia existencia, poniendo énfasis en su vida individual y, en particular, en la historia de su personalidad". En esta definición, lo que más nos interesa es la línea de coherencia que se establece en el texto autobiográfico y en el trinomio autor-narrador-personaje. Si podemos calificar ciertos textos hudsonianos como autobiográficos, es allí donde mejor encontraremos rastros de la identidad autoral.

Otras posturas teóricas suavizan el énfasis que suele ponerse en la realidad demostrable por detrás de lo narrado. James Olney, por ejemplo, considera a la autobiografía como una "metáfora del ser" (1972, p. 35), un símbolo o una representación del yo. En este sentido, la diferenciación entre autobiografía y ficción del yo (o autoficción, para usar el término de Lejeune) pasa de la comprobación de los hechos verídicos al centro simbólico de la obra puesto en el "yo".

Podría decirse que Idle Days in Patagonia sella el pacto autobiográfico planteado por Lejeune en términos de veracidad referencial ${ }^{7}$. No hay razón para dudar de los hechos narrados por Hudson y, más allá del detalle del naufragio sugerido por Wilson (2015) como de posible naturaleza ficcional, sus críticos, cuyas lecturas son de neto corte biográfico, no se han molestado hasta ahora en poner en duda la palabra del naturalista.

Podría incluso especularse con que, en un primer momento, el proyecto de escritura original (comenzado incluso una década atrás) haya sido una tentativa de novela, en la línea de The Purple Land, reciclando material autobiográfico, pero que luego fue torciéndose hacia su manera más propia y ecléctica de narrar, el estilo propiamente hudsoniano que hemos mencionado como asentado en la mezcla de géneros.

A pesar, entonces, de cumplir con el pacto autobiográfico mediante la alineación de las figuras del autor, narrador y protagonista, Hudson no insiste en echar luz o problematizar aspectos cardinales de la propia identidad, como el hecho de ser nacido en el territorio. Pensemos en el lector inglés de Hudson en 1893: el texto no explicita (aunque tampoco esconde) que el autor había nacido y crecido en Argentina, que hablaba el idioma, etc. Hudson construye en Idle Days una imagen tal vez "aséptica" que le posibilita reflexiones de índole existencial más profunda una vez que se aísla en el territorio patagónico.

Tan solo una decena de veces aparece mencionada Argentina, siempre en forma de gentilicio referido a terceros. Si bien hacia el final del capítulo X habla de "mi país" ("the melodists of my country”), el antecedente 
de esa frase no es Argentina sino Sudamérica y su declaración solo apunta a reforzar su legitimidad como sujeto supuesto saber en una disputa sobre la música de las aves:

It is clear then, from these facts and figures, that South America is not wanting in songsters, that, on the contrary, it surpasses all other regions of the globe of equal extent in number of species.

It only remains to say something on another matter - namely, the character and value of the music. And here the reader might think that I have got myself into a quandary, since I began by complaining of the unworthy opinion expressed by European writers of the melodists of my country, and at the same time disclaimed any intention of attempting to describe their melody myself, comparing it with that of England. Fortunately for my purpose, not all the travellers in South America, whose words carry weight, have turned a deaf or unappreciative ear to the bird music of the great bird continent. (1893, pp. 156-157).

Como vemos, la red lexical del texto escamotea imagológicamente la identificación entre el territorio representado y la existencia de un estado-nación.

En sus reflexiones semimísticas acerca de estados primigenios provocados por la soledad en contacto con la naturaleza, el texto de Hudson se acerca más a la concepción que Olney (1972) plantea de la autobiografía. Hudson se alinea con el grupo de escritores sobre la Patagonia que metaforiza el territorio (lo veremos definido por Livon-Grosman, 2001) y, a través de este, el naturalista semiotiza su propia identidad.

Esta imagen de Hudson solo en medio de la nada es tal vez la más simbólica que obtendremos del autor a través de su obra. En obras como Far Away and Long Ago, el yo autoral inscrito en el relato se relaciona con su entorno familiar y social, además de pasar mucho tiempo en soledad y observación de la naturaleza. Incluso las mascotas que Hudson tuvo de niño cobran protagonismo. Pero en su adultez, cuando emprende su excursión a la Patagonia, Hudson plantea desde el principio el valor que concede a reducir al mínimo su contacto con el mundo exterior o social. La escasez de noticias lo ayuda en su soledad y, cuando finalmente recibe un diario atrasado, descubre que ha perdido la costumbre y le causa extrañeza.

I was conscious on quitting the room, where I had cast aside the unread newspaper, that the old interest in the affairs of the world at large had in a great measure forsaken me; yet the thought did not seem a degrading one, nor was I at all startled at this newly-discovered indifference, though up till then I had always been profoundly interested in the moves on the great political chessboard of the world. How had I spent those fifty or sixty days, I asked myself, and from what enchanted cup had I drunk the oblivious draught which had wrought so great a change in me? The answer was that I had drunk from the cup of nature, that my days had been spent with peace. It then also seemed to me that the passion for politics, the perpetual craving of the mind for some new thing, is after all only a feverish artificial feeling, a necessary accompaniment of the conditions we live in, perhaps, but from which one rapidly recovers when it can no longer be pandered to [...]. It is easy enough to relapse from this free and pleasant condition [...]. That I have never been guilty of backsliding I cannot boast; nevertheless the lesson nature taught me in that lonely country was not wholly wasted, and while I was in that condition of mind I found it very agreeable. (1893, pp. 75-76, el subrayado es nuestro).

En esta primera etapa, Hudson valora la pequeña comunidad patagónica en la que descansa por sobre la ocupación abstracta de reflexionar acerca del panorama mundial. Con el tiempo se torna un poco más antisocial. Cuando sus anfitriones se reúnen, él se aparta cada vez con más indiferencia. Sin embargo, su planteo nunca es el de la completa soledad. El contacto con la naturaleza es una práctica espiritual que el hombre debe recuperar, pero que no desmerece la vida en comunidades pequeñas.

Ford Madox Ford (2010, pp. 168-169) describe a Hudson viviendo en un pequeño pueblo de la campiña inglesa. En la lectura de Hudson como imagen, esta anécdota es equivalente. Hudson plantea, en una línea cercana a Thoreau, que el mismo modo de vida de pequeño burgués civilizado en contacto con la naturaleza es realizable donde sea que viva. Esto, sin embargo, merece ser contrastado con lo que Jean Franco (1980, p. XLIII) llama la esterilidad de las comunidades y tipos ideales en la obra de Hudson, tal vez más evidente en obras como The Purple Land y, especialmente, A Crystal Age.

Sus referencias son siempre hacia sus lectores ingleses. Enfrentado al Río Negro por primera vez, compara el ancho de su cauce con el del Támesis a la altura de Westminster (1893, p. 23), una observación obviamente posterior a la experiencia, porque sabemos que a los treinta años Hudson nunca había visto el Támesis. 
También las referencias sociales se articulan alrededor del lector modelo. Hudson solo identifica plenamente a los ingleses con los que se cruza y que lo ayudan. Los demás personajes son a lo sumo "un italiano" o "un colono", pero el inglés siempre es “a young Englishman from Newcastle-on-Tyne” (1893, p. 3). El inglés tiene historia e identidad, mientras que los demás sujetos tienden a caer en el anonimato. Sería interesante acceder a las notas que Hudson tomó durante su viaje en 1870, muy probablemente no conservadas ¿Habrá consignado datos sobre todas las personas, eligiendo luego elidir aquellos pertenecientes a los no ingleses, o ya en esa época tenía una conciencia identitaria en la que se favorecía lo inglés por sobre lo argentino o sudamericano?

Como vimos, Hudson en escasas ocasiones se refiere a la Argentina. Alicia Jurado (1988) nota que es un rasgo común a toda su obra sobre nuestro país y dice: "[Argentina], a la que casi nunca nombra sin perífrasis, como si la palabra Argentina disipase la poesía de la imprecisión” (p. 13). Esto tiene más sentido en esta obra en particular, si tenemos en cuenta lo que dice Ernesto Livon-Grosman (2001) acerca de que la Patagonia es concebida como un territorio ajeno a la Argentina (estado-nación o no) en la tradición de relatos de viaje sobre el territorio:

[...] la idea de la Patagonia como un espacio mitológico es anterior, como tantas mitologías, a la formulación de la nación o a la existencia misma de un territorio colonial. [El territorio patagónico ofrece un] Atractivo que, en el caso de los viajeros no argentinos, se debe en parte a que estas narrativas tratan de un territorio independiente del país del que forma parte. (párr. 1).

Si bien muchas referencias están orientadas hacia el lector inglés, lo interesante es que Hudson convoca elementos de su observación de la naturaleza para delinear la propia identidad, en cuyo sustrato más profundo las filiaciones nacionales pierden protagonismo. Hasta tal punto Hudson piensa el mundo a través de la naturaleza, que la observación de las golondrinas sugiere paralelismos con su propia encrucijada espiritual. Cuando la bandada de golondrinas que observaba migra hacia el norte:

I missed them greatly, and wished that they had delayed their going, since it was easier and more hopeful to ponder on the mystery of their instinct when they were with me. That break in the tenor of their lives; the enforced change of habits; the conflict between two opposite emotions-the ties of place that held them back, seen and guessed in their actions, and the voice that called them away, speaking ever more imperatively, which so wrought in them that at moments they were beside themselves - noting all this, hearing and seeing it at all hours of the day, I seemed to be nearer to the discovery of some hidden truth than when they were no longer in sight. (1893, pp. 33-34).

Por eso la identidad de Hudson plantea un desafío de definición o descripción para todo crítico, porque el naturalista concibe mayor identificación con las aves que con las personas. Incluso podría decirse que, como la de las golondrinas, la de Hudson es una identidad migrante. Su empatía con el mundo animal lo lleva no solo a intentar comprender a la golondrina que se ve impelida a migrar, sino a adivinar su propia travesía vital en la de las aves. Cuando miraba a las golondrinas, Hudson aún no sabía que emigraría para siempre a Londres. Pero cuando escribe Idle Days, ya estaba allí hacía veinte años. Las golondrinas debían aparecérsele entonces, al repasar sus notas de campaña, como un extraño presagio del porvenir.

\section{Mirando a través de ojos vacíos}

David Viñas (1982), Susana Rotker (1999) y Jorge Bracamonte (2003) han abordado la cuestión indígena en relación con la historia argentina y el surgimiento del estado-nación, con el fin de iluminar las zonas oscurecidas por la tradición cultural en lo concerniente al exterminio sistemático de los pueblos aborígenes y al silenciamiento como política estatal. Este episodio espurio de la fundación del estado-nación argentino atraviesa, como un río subterráneo, entre alusiones y elisiones, las figuraciones imaginarias de la identidad asociada al territorio.

Sin embargo, resulta interesante cómo dichos abordajes sobre la cuestión indígena no parecen articularse con el caso de Hudson, cuyo perfil identitario se construye paralelamente a la configuración cultural del 
imaginario en torno a lo que hoy se comprende como "pueblos originarios". Más allá de lo ya señalado por Szurmuk (2001, párr. 19) acerca de cómo Hudson invisibiliza en su discurso la extinción indígena y sus connotaciones políticas (pretende preservar las aves, pero naturaliza la desaparición del indio), lo cierto es que el naturalista se posiciona políticamente como un actante póstumo, externo, en lo que respecta a esas tensiones, toda vez que la organización del estado-nación moderno en Argentina es completamente ajena a sus intereses, y su imagen identitaria es siempre comprendida más en términos de experiencia en un territorio que de ciudadanía de un estado. Su visita a la Patagonia ocurre antes de lo que la historia oficial denominó siniestramente como "Conquista del Desierto" (1879-1885), mientras que la publicación de su obra ocurre cuando dicha campaña militar ya había acabado. Hudson, como postula Szurmuk (2001), habla desde ese "tiempo diacrónico de la periferia" (párr. 16), articulando un discurso que reflexiona metafóricamente sobre el mito del espacio patagónico, antes que contribuir a una construcción simbólica del territorio que sirva para explicar su apropiación (distinción que, como veremos, aborda Livon-Grosman, 2001). No será casual que el proceso de canonización de Hudson en Argentina comience cuando sus principales mediadores críticos consulten la identidad nacional en la lectura del naturalista, los mismos que comenzaron a pensar la cuestión del carácter emblemático del campo a partir de la concepción lugoniana según la cual indio, gaucho y frontera eran componentes de una épica extinta solo destinada a producir metáforas.

Para pensar la concepción heterónoma de Hudson en esta obra, es fundamental el hecho de que el naturalista solo establece un vínculo intelectual con los indígenas in absentia. Más accidentada será la relación presencial (convivencia) para Mr. Abel en Green Mansions. Pero aún antes que con la alteridad humana, Hudson entra en contacto con animales y plantas, que siempre son su prioridad de observación. El naturalista convierte sus experiencias (incluso las más aciagas, como pasar la noche a oscuras encerrado en una cabaña helada con la pierna sangrando) en oportunidades de empatizar con la otredad a través de la observación de la naturaleza. Solo a través de plantas y animales Hudson se acerca la alteridad humana.

Gracias a la oscuridad dice comprender lo que representa el sentido del oído para los ciegos y los animales que viven en cuevas (1893, pp. 23-24). Al mirar una serpiente que bien podría haberle costado la vida, Hudson dice:

[...] the fancy is born in me that I am regarding what was once a fellow-being, perhaps one of those cruel desperate wretches I have encountered on the outskirts of civilization, who for his crimes has been changed into the serpent form, and cursed with immortality. (1893, p. 28).

La imaginación florece en el territorio fronterizo, ese espacio intersticial que confina o libera, donde prolifera la actividad semiótica; Hudson se acerca a la alteridad humana a través de una humanización de los animales. El subalterno a quien Hudson extiende su entendimiento no tiene voz ni cuerpo.

A lo largo de Idle Days (1893), el comentario sobre los pueblos indígenas, a pesar de abundar en lugares comunes del determinismo racial de la época, parte del intento de comprender su cosmovisión (pp. 39-40). Considera que fue la soledad en estrecho contacto con la naturaleza la razón de un paulatino progreso hacia un estado superior, aunque ya estén condenados a extinguirse (p. 40). La empatía de Hudson para con el indígena, sin embargo, pertenece al pasado, no implica una postura social confrontativa con el presente.

The men of the past in the Patagonian valley were alone with nature, makers of their own weapons and self-sustaining, untouched by any outside influence, and with no knowledge of any world beyond their valley and the adjacent uninhabited uplands. And yet, judging even from that dim partial glimpse I had had of their vanished life, in the weapons and fragments I had picked up, it seemed evident that the mind was not wholly dormant in them, and that they were slowly progressing to a higher condition. (p. 40).

Hudson considera que el aislamiento de los indígenas precolombinos, su soledad en contacto con la naturaleza, constituyó un factor de progreso civilizatorio que quedó trunco con la colonización. Por ende, establece aquí una distinción que resulta también fundamental en la lectura de Green Mansions, donde las valoraciones son hechas sobre pueblos indígenas cuya cultura supuestamente se ha degenerado por un 
contacto parcial con la civilización. Más allá del cliché que resulta la noción de "culturas avanzadas", cabe destacar que Hudson considera que también los ingleses fueron en el pasado como estos indígenas. Además, notemos cuál es el estado que Hudson considera ideal para el desarrollo de una civilización: "solos con la naturaleza".

[...] the wished vision of the past came unsought and unexpectedly to me, and for a while I saw nature as the savage sees it, and as he saw it in that stone age I pondered over, only without the supernaturalism that has so large a place in his mind. By taking thought I am convinced that we can make no progress in this direction, simply because we cannot voluntarily escape from our own personality, our environment, our outlook on Nature. (1893, pp. 40-42).

Aquí hay una breve pérdida de impulso en el conato empático de Hudson, que regresará renovado en el próximo capítulo. El "salvaje", para Hudson, ve la naturaleza igual que sus antepasados. Ve el pasado desde el presente. El indígena vive en un tiempo heterogéneo y, para Hudson, pertenece siempre al pasado. El segundo subrayado corresponde a una tímida admisión de subjetividad en sus juicios, a la incapacidad de abandonar la propia identidad.

If by looking into the empty cavity of one of those broken unburied skulls I had been able to see, as in a magic glass, an image of the world as it once existed in the living brain, what should I have seen? (1893, p. 44).

Observando un cráneo en un cementerio indígena, Hudson hace el mayor esfuerzo de empatía al intentar imaginarse cómo veían el mundo los habitantes de la Patagonia precolombina. A esto sigue una descripción del paisaje a través de ojos indígenas, que es el mismo que puede apreciar Hudson, y cómo el río debía ser el centro de su actividad y cosmovisión:

[...] the few Indians now inhabiting the valley are most probably modern colonists of another family or nation ; yet it did not surprise me to hear that some of these half-tame, half-christianized savages had, not long before my visit, sacrificed a white bull to the river, slaying it on the bank and casting its warm, bleeding body into the current. (1893, pp. 46-47).

Los indígenas contemporáneos a Hudson son también sujetos fronterizos (ni cristianos ni civilizados del todo), al parecer empujados a esa medianería por la misma colonización, que el naturalista deja entrever que los corrompe. Hudson incluso deja entrever que el indio es un aliado de la naturaleza en la lucha de esta contra el colono que intenta afincarse y abusar de ella implementando la civilización (1893, p. 78).

\section{No TAN DISTINTOS DESPUÉS DE TODO}

Idle Days constituye una textualidad fluida, donde las digresiones permiten mayor contacto entre las identidades. Son fundamentales los momentos en que el sujeto se identifica con elementos anteriormente considerados componentes del polo de la alteridad, como cuando Hudson describe la planta de las buenasnoches (evening primrose), que puede encontrarse tanto en Argentina como en Inglaterra. Esa parte de la naturaleza parece conectar las dos mitades de la identidad hudsoniana cuando el naturalista dice: "Its subtle fragrance, first and last, has been much to me, and has followed me from the New World to the Old, to serve sometimes as a kind of second more faithful memory" (1893, p. 7).

En el Facundo (1995), Sarmiento predica en contra del fenómeno de la indolencia, que el gaucho adquiere de la convivencia en el espacio vacío de la llanura, y lo compara con los colonos europeos:

Da compasión y vergüenza en la República Argentina comparar la colonia alemana o escocesa del Sud de Buenos Aires, y la villa que se forma en el interior: en la primera las casitas son pintadas, el frente de la casa siempre aseado, adornado de flores y arbustillos graciosos; el amueblado sencillo, pero completo, la vajilla de cobre o estaño reluciente siempre, la cama con cortinillas graciosas; y los habitantes en un movimiento y acción continuos. Ordeñando vacas, fabricando mantequilla y quesos, han logrado algunas familias hacer fortunas colosales y retirarse a la ciudad a gozar de las comodidades. La villa nacional es el reverso indigno de esta medalla: niños sucios y cubiertos de harapos viven en una jauría de perros; hombres 
tendidos por el suelo en la más completa inacción, el desaseo y la pobreza por todas partes, una mesita y petacas por todo amueblado, ranchos miserables por habitación, y un aspecto general de barbarie y de incuria los hacen notables. (p. 64).

Pero cuando Hudson se refiere a la indolencia típica de la zona, que en su caso considera causada por el clima, confiesa haberla adoptado, transformándola en el ocio feliz al que se ve obligado por su convalecencia. Así transforma un atributo propio de tierras salvajes en una actividad civilizada basada en la observación y la reflexión (y esto a pesar de que Hudson, de pequeño, ya estaba familiarizado con el vagabundeo ocioso por la pampa observando la naturaleza), en un ejemplo de semiotización que toma algo caótico para traducirlo al idioma del "civilizado" que Hudson maneja para sus lectores ingleses:

I caught nothing, and found out nothing; nevertheless, these days of enforced idleness were not unhappy. And after leaving my room, hobbling round with the aid of a stout stick, and sitting in houses, I consorted with men and women, and listened day by day to the story of their small un-avian affairs, until it began to interest me. But not too keenly. I could always quit them without regret to lie on the green sward, to gaze up into the trees or the blue sky, and speculate on all imaginable things. The result was that when no longer any excuse for inaction existed use had bred a habit in me-the habit of indolence, which was quite common among the people of Patagonia, and appeared to suit the genial climate; and this habit and temper of mind I retained, with occasional slight relapses, during the whole period of my stay. (1893, p. 20).

Recordemos lo que plantea Ricardo Piglia (1978, p. 23) acerca de cómo la canonización de Hudson constituye un factor decisivo en el proceso de inversión de la dicotomía civilización-barbarie. Textos como Idle Days, en que el sujeto no duda en adoptar para sí, y resignificar para la propia cultura, actitudes tradicionalmente endilgadas en el campo cultural argentino como signo negativo a la alteridad, son el tipo de lecturas que favoreció el criollismo.

Pero la más importante igualación del "salvaje” y el civilizado (pasado y presente) llega luego. Hudson les recuerda a los ingleses que ellos también fueron "salvajes" y que en ese momento eran más profundos que los hombres cientificistas de la actualidad:

Doubtless man is naturally scientific, and finds out why things are not what they seem, and gets to the bottom of all mysteries; but his older, deeper, primitive, still persistent nature is non-scientific and mythical, and, in spite of reason, he wonders at the change ;-it is a miracle, a manifestation of the intelligent life and power that is in all things. (1893, pp. 35-36).

Hudson incluso dice que el hombre moderno es científico por naturaleza, en un oxímoron que exhibe otra de las escisiones identitarias del anglo-argentino.

\section{VIAJE TRUNCO Y LA CATEgORÍA DEL CRUCE: CUESTIONES GENÉRICAS}

Con respecto a su estatuto genérico, Idle Days tiene una cualidad evasiva y presenta ciertas ambigüedades. Antes que nada, el carácter del viaje de Hudson se determina parcialmente a posteriori, desde la instancia de enunciación, cuando su narración se ejerce desde Inglaterra. Si Hudson hubiese permanecido en Argentina y, eventualmente, publicado su relato en español, habría sido uno más en la serie de argentinos con cierto origen extranjero que empezaban a explorar los territorios luego anexados, también influenciados por la lectura de los viajeros ingleses (Hudson ya había leído a Darwin, por lo pronto, y conocido otros textos de viajeros que circulaban en inglés y traducidos al español, véase Torre, 2003, p. 522) y probablemente en línea con las reflexiones de Lucio V. Mansilla.

Sin embargo, escribiendo en inglés desde Londres, Hudson se sitúa en una zona intersticial: realizó el viaje cuando no lo diferenciaba tanto de Moreno o de Holmberg, pero reescribió sobre sus notas en Londres, cuando se había asentado ya como un inglés más que escribe acerca de territorios coloniales y semicoloniales y luego de que su formación literaria y cultural se hubiese fundado en los románticos ingleses que leyó en la British Library. Idle Days es un texto que también quedó atrapado entre dos mundos identitarios, en un espacio liminal donde se es dos cosas a la vez y nunca se termina de ser nada. A esto habría que agregarle el carácter de escritor profesional que forja Hudson, el cual lo distingue de la mayoría de los viajeros ingleses, 
comerciantes y exploradores que ponen su experiencia por escrito con escasos logros estéticos, pues no se dedican a la literatura (Torre, 2003, p. 521).

Silvia Rosman (en Gómez y Castro-Klarén, 2012) se refiere también a esta lucha intestina en la identidad de Hudson entre dos modos de escritura:

Hay en Hudson un deseo de fidelidad al esquema clásico del viaje, de trazar el círculo que uniría destino e identidad, el retorno al hogar que pondría fin al impulso mismo de viajar, mientras que, al mismo tiempo, sus textos registran una y otra vez la futilidad de este deseo, revelando la brecha infranqueable que todo viaje conlleva, la imposibilidad de toda la vuelta. (p. 35).

Si la literatura de viajes tiene un rol en la expansión del imperialismo, ¿el relato de Hudson trabaja a favor o en contra de esa expansión? Si la pregunta en términos de intención del autor puede resultar ociosa, lo cierto es que, como construcción imagológica, el texto de Hudson produce efectos de sentido y de recepción que trascienden la instancia enunciativa original.

Mónica Szurmuk (2001, párr. 1) considera Idle Days como literatura de viajes, la cual define como "un género intermedio entre la realidad y la ficción”. Sin embargo, lo cierto es que podría decirse que Hudson ejercería en parte una subversión genérica del relato de viajes.

Idle Days comienza planteando un viaje que enseguida queda trunco, pero se convierte en una observación ociosa del entorno desde el estatismo, contrario en su propósito al relato de viajes de la avanzada del progreso, donde se busca conocer el territorio para su explotación económica. Podría decirse que Hudson viaja para construir un dispositivo de la mirada y oponer al aprovechamiento y la utilidad del progreso industrial el puro habitar en la naturaleza.

Ya hablamos de cómo este texto de Hudson funciona más en relación con la visión trascendentalista (a la manera de Thoreau) de la vida en la naturaleza que en consonancia con lo que Pratt $(2011$, p. 269) llama la "vanguardia capitalista". Hudson no es un "natural" escribiendo sobre el propio país, pero tampoco un extranjero sobre un país ajeno.

Andrea Bocco (2018) define un género más amplio y a la vez más específico que el de literatura de viajes, un marco donde tal vez resulte más fructífera la lectura de Hudson:

La literatura de frontera es para nosotros un género literario específico que cobra forma como tal hacia la segunda mitad del siglo XIX. Se trata de producciones que narran una experiencia personal de la vida de fronteras, desde el rol de militar, viajero, científico, excautivo. Su enunciador es un sujeto blanco (no aborigen), atravesado por la experiencia del cruce, cuya escritura filtra y expone esa experiencia, a partir de un discurso complejo y tensionado en una dualidad cultural e identitaria. Pero, además, este género construye tempranamente una noción de frontera que la semantiza como zona porosa, móvil, dual, de contacto de lo diverso, que se define a partir del cruce.

El corpus de este género es variado y hallamos en él dos tendencias de escritura [...]: una línea ortodoxa, que opera como propaganda y fundamento del discurso oficial roquista; y otra heterodoxa, que visibiliza al otro como una alteridad que pertenece al mismo género humano -en el sentido de Todorov [...] - y que, incluso, puede identificarse con sus reclamos y padecimientos. (pp. 45-46).

Como sujeto blanco que escribe en la segunda mitad del siglo XIX con experiencias que oscilan entre las del viajero y el científico, Hudson sin duda escribe en la zona porosa de la frontera y se inscribe en la línea heterodoxa descripta por Bocco, en especial gracias a sus reflexiones, que buscan cierto grado de empatía con los pueblos indígenas precolombinos, aunque por supuesto de forma intuitiva y menos sistemática que reclamos canónicos de la historia de la conquista, como los de Fray Bartolomé de las Casas y toda la tendencia lascasiana posterior. Hudson, en tanto viajero en 1870, se posiciona como un potencial agente traductor de esa frontera entre dos mundos semióticos, cuya labor finalmente será la de llevar las experiencias fronterizas, semiotizadas, hacia el centro de la semiosfera, en tanto escritor en Londres en 1893. Intuitivamente encuentra el espacio de la frontera y la peripecia simbólica del cruce como algo que trasciende el mero motivo del viaje, y produce un complejo sensorium de imágenes cruzadas de lo propio y lo otro.

Bocco (2018) nos recuerda la importancia del cruce como movimiento textual, que reproduce al sujeto social y que rige la construcción imagológica de las representaciones que circulan en el texto hudsoniano, 
así como en la lectura de la figura de Hudson como texto. La no pertenencia plena a su entorno de crianza (a raíz del viaje de sus padres desde Estados Unidos a Argentina), su viaje a la Patagonia y, unos años más tarde, su viaje definitivo a Inglaterra constituyen todas instancias tensionantes entre identidad y alteridad en las que, antes que la categoría fáctica de viaje, funciona la simbólica de cruce (e incluso en su sentido de mezcla). Sobre esta categoría de cruce pensamos el sentido de los términos frontera e identidad escindida. Así, las consideraciones genéricas acerca de literatura de frontera son mucho más fructíferas al aplicarse al texto hudsoniano que las de literatura de viaje, una lectura que artificialmente vendría a reforzar una supuesta vinculación con los viajeros ingleses

Ernesto Livon-Grosman (2001) estudia y delimita el corpus de la literatura sobre la Patagonia (escrita desde Inglaterra y Argentina), que clasifica en tres períodos: el primero comprende los textos previos a la Conquista del Desierto (Darwin, Falkner y Pigafetta), que inician una cartografía y un archivo del territorio patagónico desde el cientificismo positivista, pero que no brindan todavía una imagen orgánica de la región. El segundo comprende los textos posteriores a la Conquista del Desierto (Zeballos, Lista, Payró y Moreno), los cuales hacen un relevamiento del territorio que aspiran a encontrar ya deshabitado, listo para el definitivo asentamiento de comunidades "civilizadas" luego del exterminio de los pueblos indígenas. La mayoría de estos textos establece una relación directa con políticas oficiales de relevamiento de datos. El tercer período llega hasta la actualidad y comprende aquellos textos que ejercen una metaforización del territorio patagónico: Hudson y, a partir de este, Martínez Estrada, Chatwin y Theroux, principalmente a través de una red intertextual:

La región ya no se presenta como la barbarie, inexplorada y desierta, se ofrece en cambio como metáfora del porvenir, el territorio donde aún se pueden encontrar las oportunidades para llevar a cabo lo que no fue posible en otras regiones de la Argentina. (Livon-Grosman, 2001, párr. 12).

A este tercer período podría agregarse también Across Patagonia (New York, 1881) de la inglesa Florence Caroline Dixie, acerca de un viaje ecuestre que realizó entre 1878 y 1879. Si bien el texto de Dixie es anterior al de Hudson, la autora también utiliza la expresión Idle day (Korte, 2014, pp. 99-103), la cual evidentemente circulaba en el imaginario de la época. Dixie toma como modelo el texto de George C. Musters, At Home with the Patagonians, a Year's Wanderings on Untrodden Ground from the Straits of Magellan to the Rio Negro (1869-1870) (Londres, 1871), escrita diez años antes. Teniendo en cuenta esta bibliografía tan específica, valdría la pena preguntarse si Hudson leyó a Musters o a Dixie en preparación para componer su propio texto de frontera y si empezó a pensar con ellos en el territorio patagónico como una metáfora a través de la cual leer la realidad y la propia identidad.

\section{Colofón: de Hudson a Holmberg, imágenes de la Ciencia}

En 1872, Eduardo Ladislao Holmberg realizó su viaje a la Patagonia (Bahía Blanca y Río Negro), esa versión local de la gira europea que los naturalistas argentinos llevaban a cabo siguiendo los pasos de Darwin, casi como un bautismo de fuego, aunque cabe destacar que Holmberg fue en esto un precursor en su generación, solo precedido por Hudson.

Si bien este joven Holmberg tenía ya clara su vocación científica, la escasa disponibilidad de una formación académica en Historia Natural en nuestro país, así como el peso de la prestigiosa figura de Karl Burmeister, que ya parecía haber agotado todas las posibilidades del naturalismo a nivel local, lo empujaron a emprender su viaje de manera un tanto precipitada, "por tomar aire de mar, antes que respirar miasmas de anfiteatro" (Holmberg, 2008, p. 58): en fin, reforzar su educación con una experiencia de campo. Durante su viaje, Holmberg recolectó muestras que luego distribuiría entre amigos y conocidos, y llevó asimismo un detallado registro del periplo: 
A mi vuelta de la Patagonia, donde había llevado un diario de viaje, del que sólo recuerdo el principio, en el que consignaba hasta cuántas libras de presión marcaba el manómetro del vapor Patagones cuando salimos de Buenos Aires, y en el que había bastante material de observación para escribir un libro, me pareció que lo mejor era quemar dicho diario, porque no se recordaba en él ninguna aventura. (Holmberg, 2008, p. 59).

A pesar de que algunos académicos citan Viaje a Patagonia (1872) como un texto publicado (Giacchino, 1995; Abraham, 2015, quien nos reenvía a la lista bibliográfica de Cristóbal Hicken en Holmberg, 1952), no existen registros certeros de su edición. Nos basamos en el testimonio del propio Holmberg (así como en una comunicación personal con la investigadora del Conicet ${ }^{8}$ Paula Bruno, el 12 de mayo de 2019, quien realizó una exhaustiva búsqueda del material), para arriesgar que el diario de viajes del joven naturalista nunca vio la luz.

Si bien ese primer relato de viajes se vio abortado, Holmberg lo rescata de su memoria cuando, en Excursiones bonaerenses, se propone hacer un racconto de sus viajes científicos a las Sierras de Tandil a principios de la década del ochenta y resume brevemente sus anteriores incursiones en el territorio patagónico. Los posteriores informes de las expediciones de Holmberg tienen todos una finalidad de divulgación científica muy definida, dirigidos en muchos casos a autoridades oficiales que financiaban sus expediciones.

La destrucción que Holmberg ejerce sobre su primer texto resulta, sin embargo, significativa para plantear una comparación con el texto de Hudson. Por empezar, es notable cómo la eliminación del texto parece verse justificada por su falta de aporte al campo de estudio (al fin y al cabo, como dijimos, la figura de Burmeister dejaba la vara muy alta en la autoexigencia del precoz Holmberg), y, sin embargo, él expresa como principal vicio de esa bitácora el exceso de datos y la falta de aventura. En algún punto, es entonces la veleidad literaria frustrada la que lo lleva a juzgar tan duramente su texto y, a la vez, es una anticipación de la otra gran vocación de su vida: la ficción.

Ni siquiera dos años antes de Holmberg Hudson hizo también su viaje a la Patagonia, pero no sería hasta más de dos décadas después que recuperaría esas notas de campaña para componer Idle Days in Patagonia, la recolección de un viaje fructífero, pero bastante fallido. Desde el título mismo, donde califica su estadía de ociosa, se patentiza una diferencia fundamental entre las concepciones científicas de Hudson y Holmberg. El naturalismo de Hudson terminó por adoptar una expresión libre, poética, por momentos podría decirse que no científica, a pesar de que su intencionalidad original (en especial en su juventud y durante este viaje a la Patagonia) fuese científica. Sus métodos de observación eran quizás demasiado empíricos para la academia de la época, demasiado personales. Holmberg jamás podría haberse permitido estas libertades filosóficas, ocupado como estaba en fundar órganos de difusión científica y formar a la próxima generación de científicos y docentes (su veta artística la reservó para sus ficciones). El establecimiento de la ciencia nacional que Holmberg tuvo parcialmente sobre sus hombros requería una rigurosidad que Hudson podía tranquilamente dejar de lado y, en cambio, ganaba fama por sus "ensayos al aire libre" (Franco, 1980) que entretenían a londinenses hastiados de la gran urbe industrial, ávidos de pasear y avistar aves los fines de semana.

Hudson llega al punto de considerar que el ocio impuesto por el accidente que lo deja inmovilizado es condición sine qua non para la escritura de su relato:

If things had gone well with me, if I had spent my twelve months on the Rio Negro, as I had meant to do, watching and listening to the birds of that district, these desultory chapters, which might be described as a record of what I did not do, would never have been written. (1893, p. 18).

El ideal de observación de la naturaleza parece no concebir, para Hudson, su necesaria comunicación. El relato final está además desfasado con respecto al momento de los acontecimientos. Esto no hace más que contrastar con la concepción de observación de Holmberg, para quien la comunicación de sus observaciones a la comunidad científica era fundamental y cumplía también una función social de difusión y progreso. 
Resulta tal vez ocioso alimentar la imaginación de un encuentro entre Hudson y Holmberg, que muy probablemente haya ocurrido, dado sus conocidos en común (Francisco P. Moreno, Karl Burmeister, etc.). Hudson vivió tres años en Buenos Aires, de modo que el encuentro podría haber sucedido en la ciudad. Pero a la vez, como ya había hecho el Perito Moreno en su viaje a la Patagonia, por intermedio de Burmeister, con quien Hudson también colaboró, podrían haberse tratado en la estancia campestre de la familia del angloargentino. Fantasía o no, es inevitable preguntarse de qué habrán hablado dos naturalistas y futuros escritores que llevaron luego vidas tan lejanas, pero que valoraron de igual manera la aventura como fuente de conocimiento.

El cruce entre Hudson y Holmberg, en complejas posiciones de centro y periferia, habilita una comparación entre dos modelos diferentes en los que se articulan, hacia fines del siglo XIX, las fronteras entre ciencia, ficción y viaje, desde las coordenadas positivistas por medio de las cuales Holmberg transita de un naturalismo académico hacia una ciencia ficción satírica, y, por su parte, el conservadurismo tardo-romántico desde el cual Hudson concibe una imagen de la ciencia que radica más en la experiencia individual, y una ficción especulativa que aspira a una alegoría ruralista y antiindustrial.

Hudson, desde un campo literario central, se apropia del discurso de los viajeros y de la ciencia naturalista de un modo ajeno a esa institucionalización que Holmberg representaba para un campo literario e intelectual periférico como lo era entonces el de Argentina. Si Holmberg representa la vanguardia científica que busca imponerse a los viejos paradigmas retrógrados del catolicismo colonial rioplatense, Hudson, en cambio, estimula en el fervor del progreso industrial de la Inglaterra victoriana una percepción opuesta: la melancolía por el viejo mundo rural y de cultura agrícola.

Con respecto a su país de origen, el texto de Hudson no apuntaba en su concepción a ejercer una operación simbólica directa y no tuvo tampoco un peso político (pues careció de una recepción contemporánea), pero lo adquirió plenamente de manera póstuma durante su canonización en Argentina. Cuando, a partir de la década del veinte, Hudson ingresa al canon argentino, su figura no es solo literaria, sino que pasa a formar parte de un sistema de próceres de diversas extracciones, culturales y científicas. Leila Gómez (2009, p. 24) lo explica de la siguiente manera: "Los viajeros "locales", como Ameghino, Moreno y Hudson, se constituyeron en figuras paradigmáticas de la alianza discursiva entre la épica patriótica y los ideales de progreso científico de la nación moderna”.

Si bien fueron contemporáneos e incluso se conocieron ${ }^{9}$, Hudson tuvo escaso sino nulo contacto con los intelectuales argentinos durante su etapa productiva. La construcción receptiva de una serie canónica entre los viajes de estas tres figuras es una operación póstuma artificial que ejerce el campo literario argentino, teniendo en cuenta que toda instancia de mediación cultural trabaja con la artificialidad inherente a la relectura, a la traducción que ocurre en la frontera entre semiosferas.

Tal vez sea justamente debido a esta excentricidad respecto del campo literario que le hubiese correspondido de haberse quedado en el país (y según los escenarios en que desarrolló la mayoría de sus ficciones y muchos de sus textos ensayísticos) que Hudson logra una escritura fronteriza cuya ambigüedad y arte de la digresión hacen vacilar las convenciones culturales del género del relato de viajes. Asimismo, su narrativa provee un espesor de representaciones identitarias donde lo propio y lo ajeno escamotean y problematizan la categoría de argentinidad. Finalmente, la compleja metaforización del espacio patagónico vehiculiza un motivo recurrente de la mentalidad hudsoniana: el valor de la soledad en contacto con la naturaleza, la profunda mirada ociosa de quien está solo en medio de la nada.

\section{BibLiografía}

Abraham, C. (2015). La literatura fantástica argentina en el siglo XIX. Buenos Aires: Fundación Ciccus. Ara, G. (1954). Guillermo E. Hudson. El paisaje pampeano y su expresión. Buenos Aires: Universidad de Buenos Aires. Barnard, R. (2002). Breve historia de la literatura inglesa. Madrid: Alianza Editorial. 
Eva Lencina. Ocio en un país imaginario. Identidad, alteridad y cuestiones genéricas en IdLe Days ...

Barrenechea, A. M., Jitrik, N. y Rest, J. (1981). La crítica literaria contemporánea. Antología. (Vol. 1). Buenos Aires: Centro Editor de América Latina.

Beller, M. y Leerssen, J. (Eds.). (2007). Imagology: The cultural construction and literary representation of national characters. Amsterdam: Rodopi.

Bocco, A. A. (2018). Reescribir las fronteras para inscribir los conflictos socioculturales de la contemporaneidad. Cuadernos de Humanidades, 29, 43-57.

Bracamonte, J. (2003). Secuencia para una relectura de la Cuestión India en el siglo XIX argentino. CiberLetras, (10). Recuperado de http://www.lehman.cuny.edu/ciberletras/v10/bracamonte.htm

Ford, F. M. (2010). Amistades literarias. Santiago de Chile: Ediciones Universidad Diego Portales.

Franco, J. (1980). Introducción. En G. E. Hudson, La tierra purpúrea y Allá lejos y hace tiempo (pp. IX-XLV). Caracas: Biblioteca Ayacucho.

Giacchino, A. (1995). Breve biografía del naturalista argentino Eduardo Ladislao Holmberg (1852-1937). En H. L. López, A. M. Miquelarena y J. Ponte (Eds.), Ictiólogos de la Argentina: Eduardo Ladislao Holmberg (pp. 36-39). Recuperado de http://sedici.unlp.edu.ar/bitstream/handle/10915/15846/Documento_completo.pdf? sequence $=1$ \&isAllowed $=\mathrm{y}$

Gómez, L. (2009). Iluminados y tránsfugas. Relatos de viajeros y ficciones nacionales en Argentina, Paraguay y Perú. Madrid-Frankfurt: Iberoamericana-Vervuert.

Gómez, L. y Castro-Klarén, S. (Eds.). (2012). Entre Borges y Conrad. Estética y territorio en William Henry Hudson. Madrid-Frankfurt: Iberoamericana Vervuert.

Holmberg, E. L. (2008). Excursiones bonaerenses por Eduardo Holmberg. [Comentarios de Juan Carlos Chebez y Bárbara Gasparri]. Buenos Aires: Albatros.

Holmberg, L. (1952). Holmberg, el último enciclopedista. Buenos Aires: Francisco A. Colombo.

Hudson, W. H. (1893). Idle Days in Patagonia. London: Chapman \& Hall.

Hudson, W. H. (1895). The Naturalist in La Plata. London: Chapman \& Hall.

Hudson, W. H. (1918). Far Away and Long Ago. A History of My Early Life. London: Dent \& Sons.

Hudson, W. H. (1920). El Ombú. London: Duckworth \& Co.

Hudson, W. H. (1922). The Purple Land. Being the Narrative of one Richard Lambs Adventures in the Banda Orientál, in South America, as told by Himself. London: Duckworth \& Co.

Hudson, W. H. (1937). A Crystal Age. New York: E.P. Dutton.

Hudson, W. H. (1937). Green Mansions. New York: Alfred A. Knopf.

Hudson, W. H. (2018). Aves pamperas. (D. Gallegos, trad.). Recuperado de https://studylib.es/doc/8307534/avespamperas---folklore-tradiciones

Jurado, A. (1988). Vida y obra de W.H. Hudson. Buenos Aires: Emecé.

Korte, B. (2014). Against Busyness: Idling in Victorian and Contemporary Travel Writing. En M. Fludernik y M. Nandi (Eds.), Idleness, Indolence and Leisure in English Literature (pp. 215-234). London: Palgrave Macmillan.

Leerssen, J. (2016). Imagology: On using ethnicity to make sense of the world. Iberic@al, (10), 13-31. Recuperado de http://iberical.paris-sorbonne.fr/wp-content/uploads/2017/02/Pages-from-Iberic@l-no10automne-2016-Final-2.pdf

Lejeune, P. (1994). El pacto autobiográfico y otros estudios. Madrid: Megazul-Endymion.

Liedke, H. (2018). The Experience of Idling in Victorian Travel Texts, 1850-1901. London: Palgrave Macmillan.

Livon-Grosman, E. (2001). Lo abierto y lo cerrado: el espacio patagónico en la literatura de viaje. CiberLetras, (5). Recuperado de http://www.lehman.cuny.edu/ciberletras/v05/grosman.html

Livon-Grosman, E. (2003). Geografias imaginarias. El relato de viajes y la construcción del espacio patagónico. Rosario, Argentina: Beatriz Viterbo. 
Lotman, I. M. (1996). La semiosfera I. Semiótica de la cultura y del texto. (D. Navarro, trad.). Recuperado de https://www.academia.edu/38723943/La_semiosfera_I_Semi\%C3\%B3tica_de_la_cultura_y_del_texto? auto $=$ download

Morillas Ventura, E. (2005). Sensaciones y sensibilidad en Días de ocio en la Patagonia. En La literatura bispanoamericana con los cinco sentidos (pp. 457-464). Recuperado de https://ruc.udc.es/dspace/bitstream/ handle/2183/11390/CC-78\%20art\%2052.pdf?sequence=18isAllowed=y

Olney, J. (1972). Metaphors of Self. The Meaning of Autobiography. New Jersey: Princeton University Press.

Piglia, R. [Firmado como Emilio Renzi]. (1978). Hudson: ¿Un Güiraldes inglés? Punto de Vista, (1), 23-24.

Pratt, M. L. (2011). Ojos imperiales. Literatura de viajes y transculturación. México: Fondo de Cultura Económica.

Rotker, S. (1999). Cautivas. Olvidos y memoria en la Argentina. Buenos Aires: Ariel.

Sarmiento, D. F. (1995). Facundo. Barcelona: Altaya.

Sartre, J. P. (2005). Lo imaginario. Psicología fenomenolófgica de la imaginación. Buenos Aires: Losada.

Selnes, G. (2003). The Metaphoricity of Shipwrecks; or, Exile (not) Considered as One of the Fine Arts. CiberLetras, (10). Recuperado de http://www.lehman.cuny.edu/ciberletras/v10/selnes.htm

Szurmuk, M. (2001).Visto, oído, recordado: William Henry Hudson viaja a la Patagonia. Ciberletras, (5). Recuperado de http://www.lehman.cuny.edu/ciberletras/v05/szurmuk.html

The Editors of Encyclopaedia Britannica. (2016). Pastoral Literature. Encyclopaedia Britannica. Recuperado de https://www.britannica.com/art/pastoral-literature

Thomassen, B. (2009). The Uses and Meanings of Liminality. International Political Anthropology, 2(1). 5-27.

Tomalin, R. (1982). W.H. Hudson. A Biography. London: Faber and Faber.

Torre, C. (2003). Los relatos viajeros. En J. Schvartzman (Dir.), Historia critica de la literatura argentina. La lucha de los lenguajes (Vol. 2, pp. 517-538). Buenos Aires: Emecé.

Velázquez, L. H. (1963). Guillermo Enrique Hudson. Buenos Aires: Ediciones Culturales Argentinas.

Viñas, D. (1982). Indios, ejércitos y frontera. México: Siglo XXI.

Wilson, J. (2015). Living in the Sound of the Wind, A Personal Quest for W.H. Hudson, Naturalist and Writer from the River Plate. London: Constable.

\section{Notas}

1 Como una de las disciplinas fundacionales de la Literatura Comparada, la Imagología estudia las imágenes de lo nacional como representaciones discursivas en textos literarios, así como las identidades nacionales que los sujetos conforman discursivamente a partir del contacto con la alteridad. El objetivo central de la Imagología consiste en deconstruir el discurso del esencialismo nacional y étnico (Leerssen, 2016, p. 13). El concepto central sobre el que gira la Imagología es el de imagen (también referido como imagotipo o incluso etnotipo), que puede definirse como toda representación discursiva de una persona, grupo, etnicidad o nación concerniente a atribuciones morales o caracterológicas (Beller y Leerssen, 2007, p. 342). Una imagen cambia según la perspectiva del enunciador: la auto-imagen es aquella que en determinado texto se proyecta en torno a la propia identidad del sujeto; la hetero-imagen, por el contrario, es la que el sujeto construye en torno a la alteridad.

2 En la Semiótica de Iuri Lotman (1996), el concepto de frontera se refiere a la serie de traductores o filtros que median entre la semiosfera (ese continuum ocupado por formaciones semióticas de diversos tipos y en distintos niveles de organización) y el espacio alosemiótico, donde es imposible la existencia de la semiosis. La función de la frontera consiste en filtrar las significaciones externas y, mediante un proceso de semiotización, traducir un texto a un lenguaje o código comprensible por la semiosfera receptora. Según Lotman (1996, pp. 13-14), "la frontera es un mecanismo bilingüe que traduce los mensajes externos al lenguaje interno de la semiosfera y a la inversa”, es decir, hacer de lo alosemiótico, semiótico. La función de la frontera consiste también en limitar penetraciones externas, filtrar ese contenido y elaborarlo adaptativamente. La frontera, por ser una zona de contacto, es un espacio donde se concentra incluso mayor actividad semiótica que en el centro de la semiosfera. Al determinar cuáles son las culturas implicadas y percibidas en los discursos estudiados, tomamos de los textos de Hudson precisamente el problema de esa doble perspectiva (a la que nos referimos como identidad escindida), desde la cual al sujeto le es posible construir una imagen de lo argentino/americano como un 
otro desde una mirada identificada con la pertenencia a una colectividad anglosajona, pero también reproducir la imagen de lo argentino/americano como parte de lo propio frente a la mirada ajena de la sociedad inglesa en la cual Hudson se inserta como un no-inglés.

3 Uno de los capítulos, "The War Wtih Nature”, se había publicado en 1883 en la revista Merry England bajo el título de "The Settler's Recompense", por lo que sabemos que hacía al menos diez años que trabajaba en el texto antes de su publicación.

4 Según Jason Wilson (2015, p. 112), Hudson le mencionó a un conocido que el viaje duró un año, entre 1870 y 1871 y no habría razón para dudar de su palabra. Si bien Luis Horacio Velázquez (1963, p. 127) dedujo y defendió que la estancia de Hudson duró desde octubre de 1870 hasta marzo de 1872, esto constituye una deducción aproximativa surgida de la correspondencia de Hudson, quien anuncia su viaje en una carta a Sclater a principios de septiembre de 1870 (Hudson, 2018, p. 64. Traducción de la correspondencia de Hudson con respecto a la ornitología, recopilada por David R. Dewar originalmente bajo el título de Letters on the Ornithology of Buenos Ayres) y cuya comunicación es publicada en los Proceedings de la Sociedad Zoológica de Londres en marzo de 1872 (p. 71), presumiblemente varios meses después de concluido el viaje. Ruth Tomalin (1982, p. 93) sitúa la llegada de Hudson a la Patagonia en diciembre de 1870 y considera que el viaje se habría extendido hasta por lo menos la primavera siguiente, señalando también el ensayo de Hudson que se publicó en los Proceedings en marzo de 1872 como el punto final del viaje, mientras que Alicia Jurado (1988, p. 59) lo sitúa sencillamente en 1871. Podría decirse entonces que el viaje comenzó en diciembre de 1870 y la estadía de Hudson se extendió durante la mayor parte de 1871.

5 Lo opuesto podría decirse de Conrad y sus travesías marinas, pero también de Melville, al cual Hudson leyó en la época de composición de Idle Days y de cuyo Moby Dick se sospecha que inspiró no solo el capítulo dedicado a la discusión de lo blanco en la naturaleza, sino también el tormentoso comienzo en barco (Liedke, 2018, p. 149, considera que coincide con una novela de aventuras con ecos de Melville).

6 La literatura pastoral es una corriente que tiende a presentar la sociedad rural como exenta de la complejidad y corrupción de la vida urbana. En la poesía inglesa, el pastoralismo comienza célebremente con el isabelino Edmund Spenser y la publicación, en 1579, de The Shepheardes Calender. Sin embargo, el género evolucionó y cobró gran importancia en la literatura inglesa del siglo XVIII y XIX, como una expresión de nostalgia respecto al mundo rural que se abandonaba en favor de las grandes ciudades y la industrialización. Grandes exponentes de este pastoralismo inglés fueron John Milton, William Wordsworth, el romántico Percy Bysshe Shelley, John Clare, etc. (Barnard, 2002, pp. 28-30; Encyclopaedia Britannica, 2016).

7 Cabe aclarar que, en este específico caso, cuando hablamos de "veracidad referencial" lo hacemos en términos de la distinción autobiografíalautoficción, que establece Lejeune, basada en la noción de pacto autobiográfico que implica la voluntad del autor de establecer una correspondencia entre el texto y los hechos comprobables de la vida. Ahora bien, en la medida en que abordamos nuestro estudio desde la teoría imagológica, tengamos presente que las imágenes de lo nacional carecen de un trasfondo veritativo, puesto que incluso en textos donde se selle ostensiblemente el pacto autobiográfico, tales imágenes siguen siendo representaciones del imaginario, construidas como efectos de sentido o incluso estereotipos de inconsciente origen literario. Recordemos que Leerssen (2016) advierte sobre el peligro de la falacia caracterológica: los hechos narrados por Hudson constituyen un objeto discursivo.

8 CONICET: Consejo Nacional de Investigaciones Científicas y Técnicas, principal organismo dedicado a la promoción de la ciencia y la tecnología en Argentina, dependiente del Ministerio de Ciencia, Tecnología e Innovación de la Nación.

9 Por intermedio de Burmeister, Hudson conoció a Moreno en 1873 (Wilson, 2015, p. 116). 